\title{
$\mathrm{Cu}-\mathrm{Al}-\mathrm{Ni}$ 계 금속간화합물의 연소합성 Coating에 미치는 Ball Mill처리의 영향
}

\author{
이 한 영" \\ 계명대학교 신소재공학과

\section{The Effect of Ball-milling Energy on Combustion Synthesis Coating of Cu-Al-Ni Based Intermetallics}

\author{
Han-Young Lee \\ Dept. of Advanced Materials Engineering, Keimyung university \\ (Received October 2, 2010; Revised November 30, 2010; Accepted December 4, 2010)
}

\begin{abstract}
The possibility of $\mathrm{Cu}-\mathrm{Al}-\mathrm{Ni}$ intermetallic coating on the mild steel through the combustion synthesis has been investigated. In particular, the effect of the ball milling energy on the microstructure of the coating layer was examined to obtain the best coating condition. Experimental results show that $\mathrm{Cu}-\mathrm{Al}-\mathrm{Ni}$ powder compact was explosively synthesized and successfully coated with the steel matrix. It was revealed that the formation of $\mathrm{Cu}_{9} \mathrm{Al}_{4}$ intermetallic decreased with increase in the ball milling energy. This result supports that the high energy ball milling would be effective for obtaining the most suitable microstructure for $\mathrm{Cu}-\mathrm{Al}-\mathrm{Ni}$ coating layer. However, the excessive ball milling energy seems to decrease the bonding strength between the coating layer and the matrix.
\end{abstract}

Keywords - $\mathrm{Cu}-\mathrm{Al}-\mathrm{Ni}(\mathrm{Cu}-\mathrm{Al}-\mathrm{Ni})$, intermetallic(금속간화합물), coating(코팅), microstructure(미세조직), ball milling energy(볼밀링에너지)

\section{1. 서 론}

Cu-Al-Ni계 금속간화합물은 열적 안정성이 우수하고 비교적 높은 변형율에서도 초탄성적인 성질을 나타낼 뿐 만 아니라 양호한 damping특성을 가지는 소재로 알려져 있다[1]. 그러나 이 화합물은 용해 및 주조방식으로 제 조[2-5]할 경우, 탄성 이방성이 현저할 뿐만 아니고 조 대한 결정립으로 인해 가공이 어려운 것으로 알려져 있 다[5]. 그래서 최근은 실용화를 위해 결정립을 조절하 는 합금성분을 첨가하거나 HIP[6-8]이나 Mechanical Alloying에 의해 제조하여 압출하는 연구[5]가 진행되고 있다.

저자는 그간 $\mathrm{Ni}-\mathrm{Al}$ 계 금속간화합물을 금속재료 위에 연소합성 코팅하여 그 적용 가능성을 확인하였다 $[9,10]$

\footnotetext{
‘주저자·책임저자 : lhy@kmu.ac.kr
}

이러한 측면에서 $\mathrm{Cu}-\mathrm{Al}-\mathrm{Ni}$ 계 금속간화합물도 코팅이 가 능하다면 이 합금의 우수한 특성을 유효하게 활용할 수 있을 것으로 생각된다. 그런데 이들을 hot press 속에서 연소합성 코팅하면 승온 과정 도중에 중간상이 생성되 어 최종적으로 화학양론적인 상과 다상조직을 형성하는 것 $[9,10]$ 으로 알려져 있다. $\mathrm{Cu}-\mathrm{Al}-\mathrm{Ni}$ 계 금속간화합물의

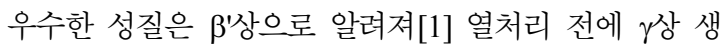
성을 최소화할 필요가 있다. 이러한 구성상을 제어를 위한 방법으로 고주파 가열장치를 활용하는 연소합성 코팅[11] 기술이 제안되어 있으나 사실 낮은 온도에서 연소합성이 일어난다면 동일한 효과를 기대할 수 있을 것으로 생각된다. 최근 금속간화합물을 ball mill에 의 해 mechanical alloying할 경우 연소합성 개시온도가 현저히 낮아진다는 사실이 밝혀졌다[12]. 따라서 연소 합성 코팅시 ball mill 처리 합금분말을 사용한다면 연 
소합성 개시온도가 저하할 것이므로 hot press에서도 구성상의 제어가 가능할 것이 생각된다.

그래서 본 연구에서는 3종류의 에너지 레벨로 ball mill 처리한 $\mathrm{Cu}-\mathrm{Al}-\mathrm{Ni}$ 합금분말의 연소합성 반응의 여 부를 검토하고 진공 hot press 속에서 철강재료 위에 연소합성 코팅시켰다. 그리고 ball milling 에너지에 따 른 공냉과정에서 일어나는 $\beta \Leftrightarrow \alpha+\gamma$ 의 공석반응 $\left(565^{\circ} \mathrm{C}\right)$ 에 의한 구성상을 조사하여 $\mathrm{Cu}-\mathrm{Al}-\mathrm{Ni}$ 계 금속간화합물 의 연소합성 코팅의 가능성을 조사하는 것을 본 연구 의 목적으로 하였다.

\section{2. 실험방법}

본 연구에서는 $99.9 \%$ 의 순도를 가진 $3 \mu \mathrm{m}$ 크기의 $\mathrm{Al}$ 과 $\mathrm{Ni}$ 분말과 $5 \mu \mathrm{m}$ 크기의 $\mathrm{Cu}$ 분말을 소정의 화학 조성 $(82.9 \mathrm{wt} \% \mathrm{Cu}-13.6 \mathrm{wt} \% \mathrm{Al}-3.5 \mathrm{wt} \% \mathrm{Ni})$ 이 되도록 칭 량하였다. 이후 이들 혼합분말 $10 \mathrm{~g}$ 을 stainless 용기에 장입하고 48시간 ball mill 처리하였다. 이때 혼합분말 과 볼의 무게비를 $1: 0,1: 3,1: 10$ (이하 각각 CAN1 재, CAN2재, CAN3재)으로 하여 3종류의 혼합분말을 제조하고 이후 이들 혼합분말 $0.1 \mathrm{~g}$ 을 냉간 press에서 $45 \mathrm{kN}$ 의 하중에서 5 분간 유지하여 직경 $6 \mathrm{~mm}$ 의 압분 체로 제조하였다.

코팅 기판재로는 시판되는 직경 $10 \mathrm{~mm}$ 일반구조용 탄소강인 $\mathrm{SM} 45 \mathrm{C}$ 환봉을 높이 $8 \mathrm{~mm}$ 로 절단한 후 코팅 면을 polishing 하였다.

연소합성 코팅은 진공 Hot press 속에서 압분체를

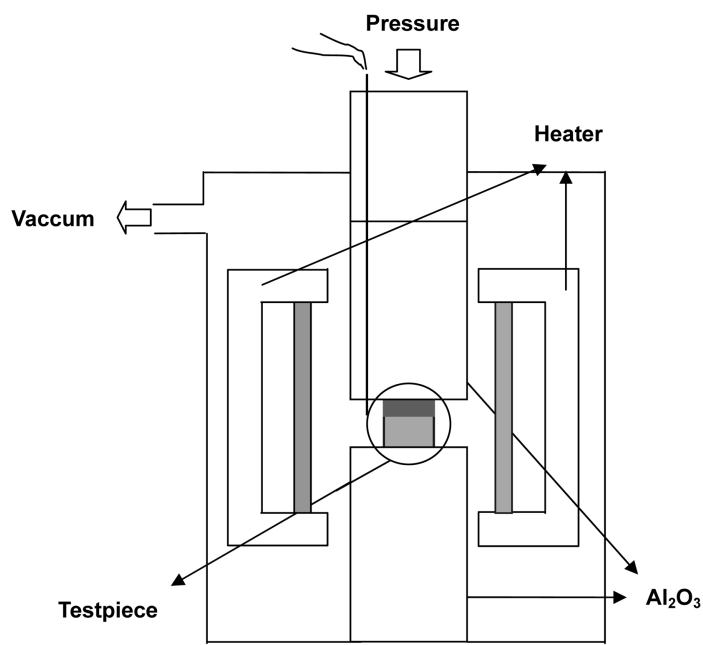

Fig. 1. Schematic diagram of hot press.
기판재위에 놓고 하중 $33 \mathrm{MPa}$ 의 압력 하에서 행하였 다. Fig. 1에 본 연구에서 사용된 진공 Hot press 장 치의 모식도를 나타내었다. 처리는 실온에서 $20^{\circ} \mathrm{C} / \mathrm{min}$ 의 속도로 $700^{\circ} \mathrm{C}$ 까지 가열을 하고 이 온도에서 30 분 유지 후, 공기를 주입하여 공냉 하였다.

또한 압분체의 발열량을 조사하기 위하여 $\mathrm{DSC}$ (시차

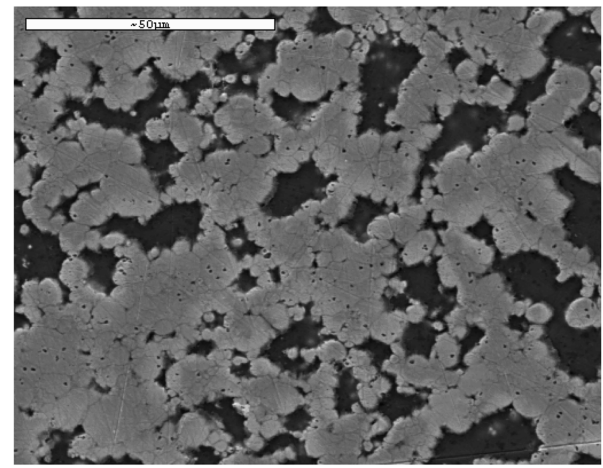

(a) CAN1

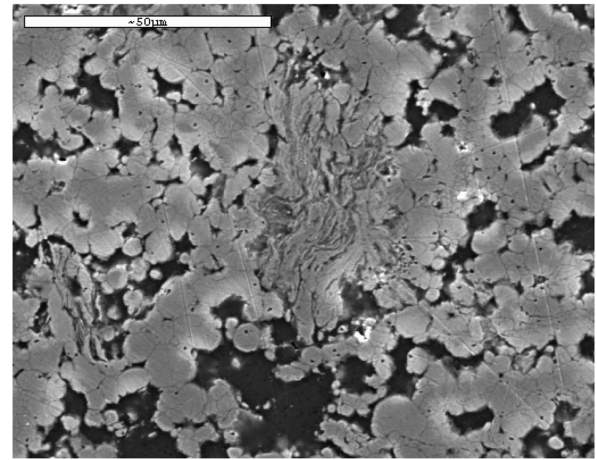

(b) CAN2

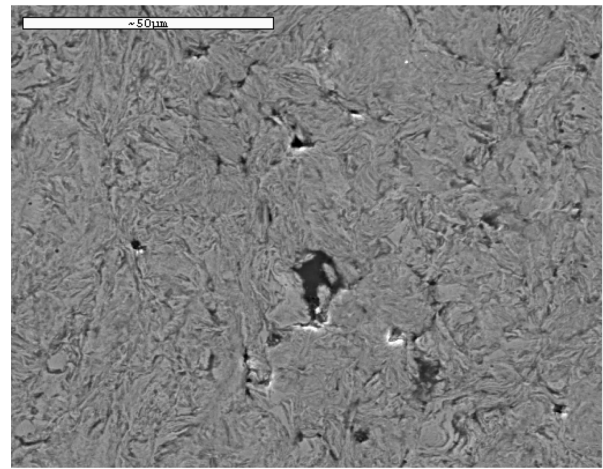

(c) CAN3

Fig. 2. Microstructure on each powder compact. 

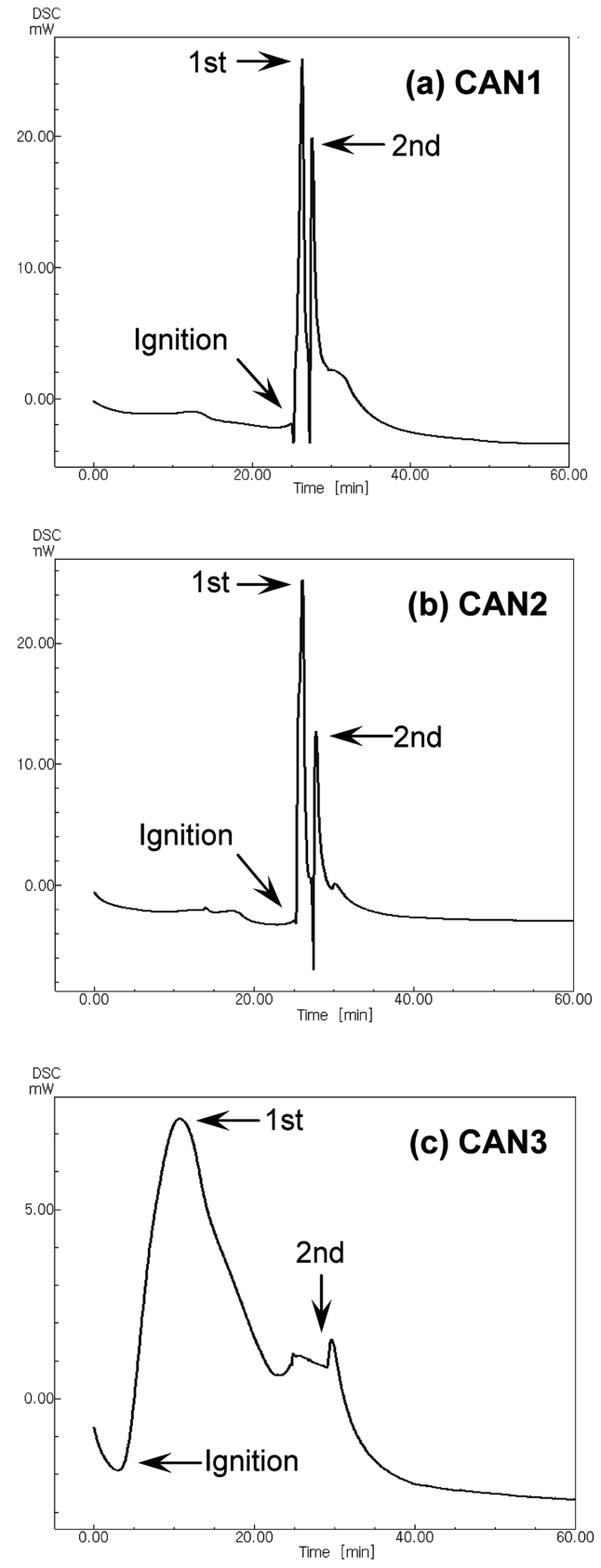

Fig. 3. DSC curve of each powder compact.
주사열량계) 분석을 하였다. 이때 시료는 대기 중에서 $650^{\circ} \mathrm{C}$ 까지 분당 $20^{\circ} \mathrm{C}$ 로 승온하였고 30 분 유지 후 공 냉시켰다.

\section{3. 실험결과 및 해석}

\section{3-1. DSC분석 전후 압분체의 조직}

Fig. 2는 냉간 press에서 제작된 압분체의 SEM사진 을 나타낸 것이다. $\mathrm{EDS}$ 분석결과 검은 부위가 $\mathrm{Al}$ 이고

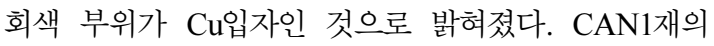
경우 $\mathrm{Cu}$ 와 $\mathrm{Al}$ 이 각각 cluster를 형성하고 있으나 ball mill 에너지가 증가할수록 $\mathrm{Al}$ 의 밀집부위가 현저히 감 소되어 분산이 잘 이루어 진 것을 확인할 수 있다. 특 히 $\mathrm{CAN} 3$ 의 경우는 $\mathrm{Al}$ 의 cluster가 전혀 관찰되지 않 고 입자들이 서로 압착되어 lamella 층을 형성하고 있 는 것을 알 수 있다. 후술하나 이들 압분체는 XRD결 과 어느 것도 ball milling 도중 연소합성은 일어나지 않은 것으로 확인되었다.

Fig. 3은 이들 압분체의 DSC trace를 나타내었고 Table 1은 이들을 분석한 결과를 나타내었다. Fig. 3에 서 보듯이 어느 것도 2 개 이상의 발열 peak가 관찰되 어 이들도 연소합성반응이 일어나는 것을 확인할 수 있다. 그리고 ball milling 에너지가 증가할수록 연소합 성개시온도(Ignition temperature) 및 peck온도가 낮아 지고 있음을 알 수 있다. 그러나 총 발열시간 및 총 발열량은 ball milling 에너지가 낮은 CAN2에서는 거 의 영향이 없으나 $\mathrm{CAN} 3$ 에서 현저히 증가한 것을 알 수 있다.

Fig. 4는 압분체를 전기로에서 $\mathrm{EDS}$ 분석과 동일한 열이력으로 열처리하기 전후에 X선회절(XRD) 시험한 결과를 나타낸 것이다. 열처리 전에는 (a)와 같이 ball milling 에너지와 관계없이 모두 미합성된 $\mathrm{Cu}$ 와 $\mathrm{Al}$ 만 으로 구성되어 있는 것으로 밝혀졌다. 이에 반해 열처 리 후(b)에는 $\alpha$ 상과 $\gamma\left(\mathrm{Cu}_{9} \mathrm{Al}_{4}\right)$ 상으로만 구성되어 있으 나 전반적으로 ball milling 에너지가 증가할수록 $\gamma$ 상 이 감소하고 $\alpha$ 상의 양이 많아지는 것을 볼 수 있다.

Table 1. Analysis results of each DSC traces

\begin{tabular}{|c|c|c|c|c|c|}
\hline & Ignition Temperature & $1^{\text {st }}$ Event Temperature $2^{\text {nd }}$ & Event Tempe & ion of Exotherm & Overall Heat \\
\hline CAN1 & $547.18^{\circ} \mathrm{C}$ & $575.32^{\circ} \mathrm{C}$ & $600.85^{\circ} \mathrm{C}$ & $14.3 \mathrm{~min}$ & $309.82 \mathrm{~J} / \mathrm{g}$ \\
\hline CAN2 & $547.07^{\circ} \mathrm{C}$ & $568.72^{\circ} \mathrm{C}$ & $592.44^{\circ} \mathrm{C}$ & $13.5 \mathrm{~min}$ & $280.97 \mathrm{~J} / \mathrm{g}$ \\
\hline CAN3 & $100.56^{\circ} \mathrm{C}$ & $257.98^{\circ} \mathrm{C}$ & $530.53^{\circ} \mathrm{C}$ & $39.3 \mathrm{~min}$ & $703.70 \mathrm{~J} / \mathrm{g}$ \\
\hline
\end{tabular}




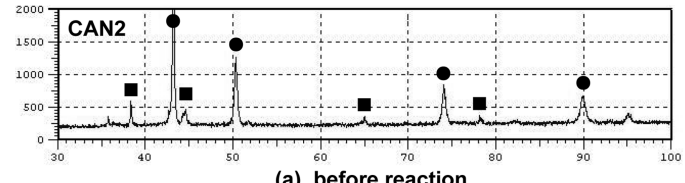

(a) before reaction

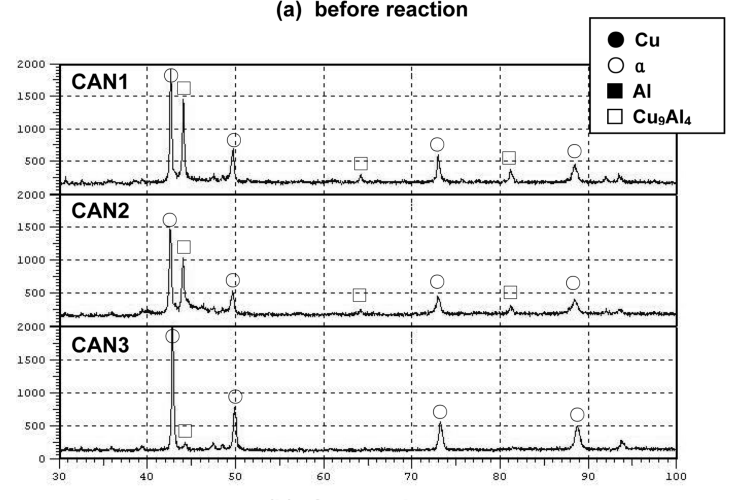

(b) after reaction

Fig. 4. Results of X-ray Diffraction on powder compact before/after reacting in electric furnace.

본 연구에 사용된 시편의 화학조성은 상태도[13]에 의 하면 $700^{\circ} \mathrm{C}$ 부근에서 $\beta$ 상 $\left(\mathrm{Cu}_{3} \mathrm{Al}\right)$ 과 $\gamma\left(\mathrm{Cu}_{9} \mathrm{Al}_{4}\right)$ 상이 생 성된 후 냉각과정에서 $\beta \rightarrow \alpha+\gamma$ 로 공석변태 $\left(565^{\circ} \mathrm{C}\right.$ 부근) 하는 것으로 추정된다. 따라서 DSC trace에서 발열 peak는 $\gamma$ 상의 형성과 관계된 것으로 생각된다. 따라서 ball milling 에너지의 증가는 연소합성에 의한 $\gamma$ 상 생 성을 억제하는 것이 분명하다. 이것은 Fig. 2에서 보듯 이 ball milling 에너지가 높을수록 $\mathrm{Al}$ 의 분산이 현저 하여 Al-rich인 $\gamma$ 상 생성이 어려워지기 때문으로 생각 된다.

Fig. 5은 $\mathrm{DSC}$ 분석 후의 각 압분체의 $\mathrm{SEM}$ 사진을 나타낸 것이다. CAN1재의 경우는 일부 기공이 존재하 나 거의 유사한 조직을 나타내고 있다. 그러나 입상의 $\gamma$ 상은 ball milling 에너지가 높아질수록 감소하고 있 고 $\mathrm{CAN} 3$ 는 대부분 $\alpha$ 상의 기지만 구성된 것을 확인 할 수 있어 Fig. 4의 XRD 결과와 일치한다.

\section{3-2. 연소합성에 의한 coating층의 미세조직}

Fig. 6은 진공 Hot press에서 ball milling 에너지가 상이한 3종류의 압분체를 철강재료 위에 각각 연소합 성 코팅된 계면 부근의 $\mathrm{SEM}$ 사진을 나타낸 것이다. 그 림에서도 알 수 있듯이 CAN1과 CAN2는 모재와 양 호한 접합이 이루어진 것을 알 수 있다. 그러나 $\mathrm{CAN} 3$ 의 계면에 국부적으로 그림과 같이 균열이 관찰 되어 밀착성에 문제가 있는 것으로 밝혀졌다. 이는

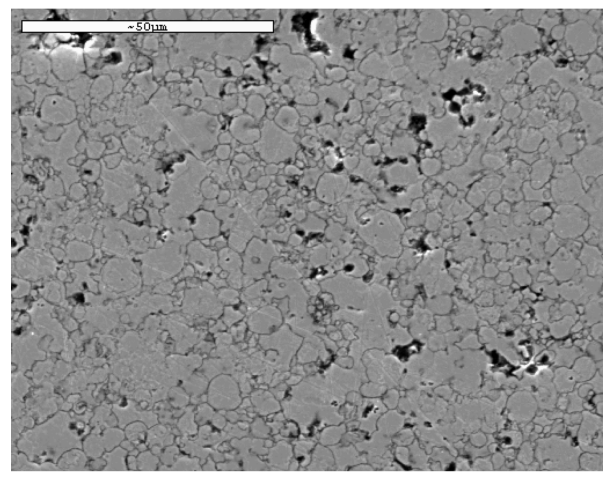

(a) CAN1

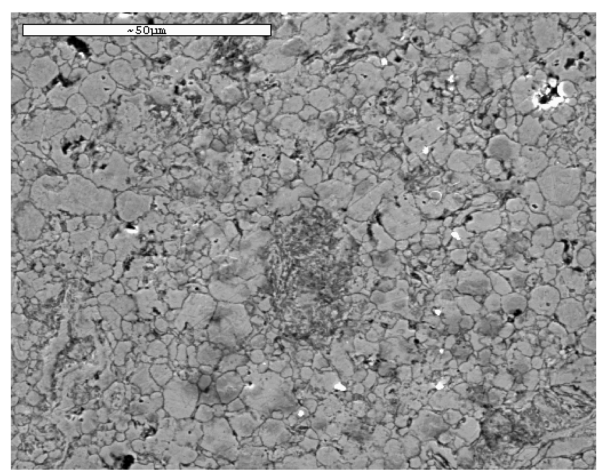

(b) CAN2

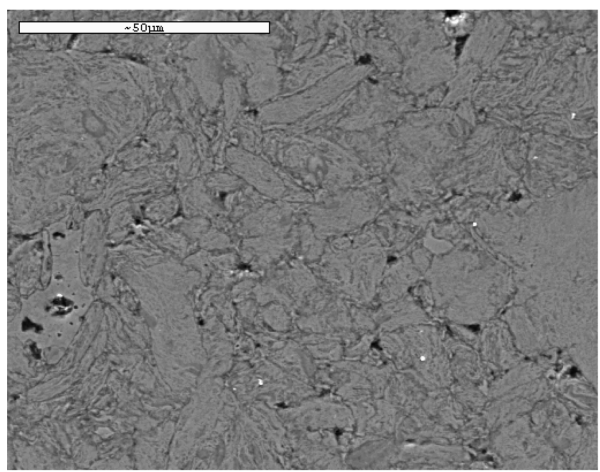

(c) CAN3

Fig. 5. SEM Microstructures of each compact after DSC analysis.

Table 1에서 보듯이 CAN3재는 총 발열량은 크나 총 발열시간이 길어 열이 분산되었을 뿐만 아니라 peak온 도도 낮아 모재와의 결합이 불완전하게 일어났기 때문 으로 생각된다.

Fig. 7은 이들 코팅층을 $X$ 선분석한 결과를 나타낸 


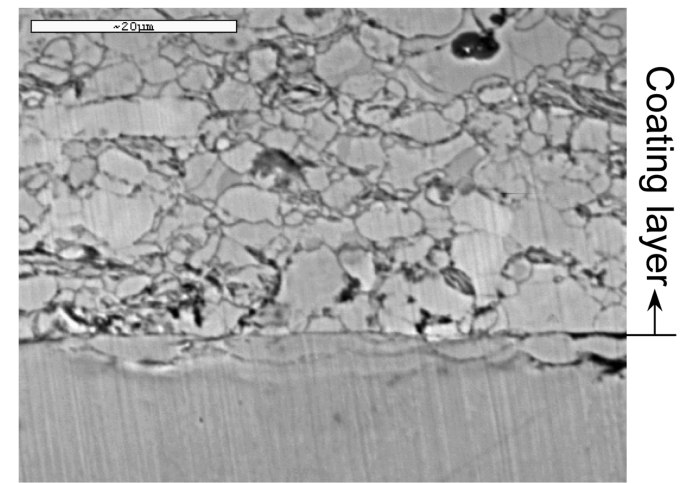

(a) CAN1

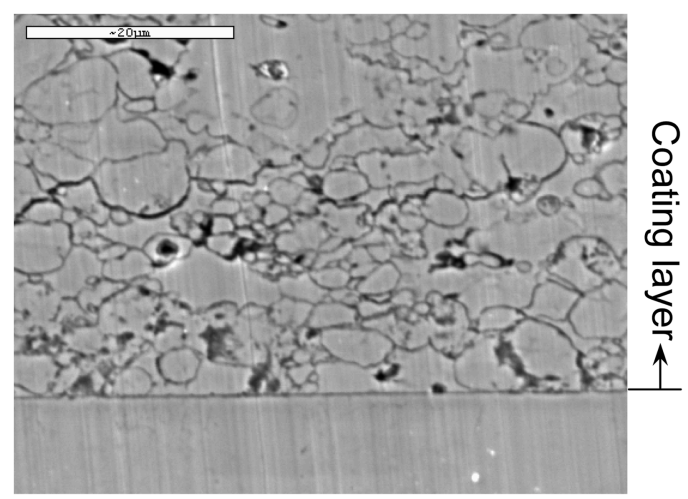

(b) CAN2

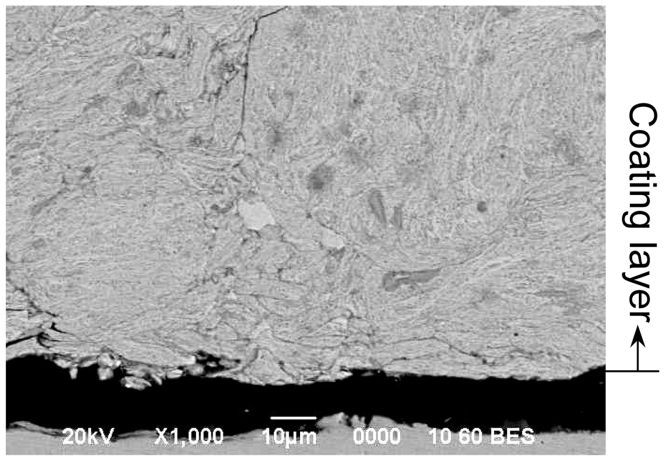

(c) CAN3

Fig. 6. SEM images of coating layer on steel.

것이다. 이 경우도 Fig. 4와 동일하게 ball milling 에 너지가 높을수록 $\gamma$ 의 생성이 감소하는 것이 확인된다. 그러나 $\alpha$ 상에 대한 $\gamma$ 상의 상대적인 비율이 현저히 증가한 것을 알 수 있다. 이것은 기판재의 존재로 냉 각속도가 감소하였기 때문으로 추정된다.

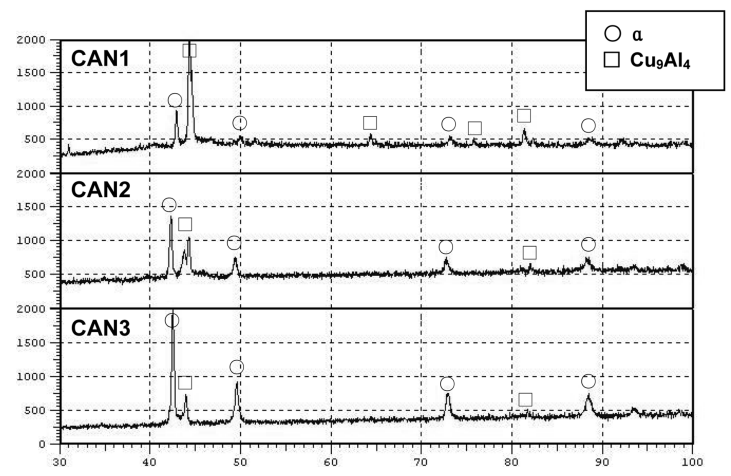

Fig. 7. Results of X-ray diffractometry on each coating layer after combustion synthesis.

\section{4. 결 론}

철강재료 위에 $\mathrm{Cu}-\mathrm{Al}-\mathrm{Ni}$ 계 금속간화합물의 연소합 성 코팅의 가능성을 조사하기 위하여 ball mill 처리 합금분말의 연소합성 후 공석반응을 조사한 결과, 다 음과 같은 결론을 얻었다.

1) $\mathrm{Cu}-13.6 \mathrm{wt} \% \mathrm{Al}-3.5 \mathrm{wt} \% \mathrm{Ni}$ 압분체는 연소합성이 일 어나고 철강재료 위에 코팅도 가능한 것으로 밝혀졌다.

$2)$ 이들은 연소합성에 의해 $\gamma\left(\mathrm{Cu}_{9} \mathrm{Al}_{4}\right)$ 상이 생성되나 이후 냉각 시 $\beta$ 상이 공석반응에 의해 $\alpha$ 상 $+\gamma$ 상 혼합 조직으로 나타나나 ball milling 에너지가 클수록 $\gamma$ 상 생성이 감소하는 것으로 밝혀졌다. 이것은 ball mill 처리에 따른 분말의 혼합성 증대에 따른 것으로 생각 되었다.

3) 이러한 측면에서 ball milling 처리에 의해 다량 의 $\alpha$ 상이 생성되는 것으로 밝혀져, 후 열처리에 의해 $\beta^{\prime}$ 상 생성을 촉진할 수 있을 것으로 생각되었다. 그러 나 ball milling 시 과도한 에너지 부여는 코팅층과 모 재사이의 밀착력 저하를 초래할 수 있다.

\section{참고문헌}

1. N.Suresh and U.Ramamurty, "Aging Response and its Effect on the Functional Properties of $\mathrm{Cu}-\mathrm{Al}-\mathrm{Ni}$ Shape Memory Alloys," J. Alloys and Compounds, Vol. 449, pp. 113-118, 2008.

2. S.Stanciu and L.G.Bujoreanu, "Formation of $\beta 1$ ' stress-induced martensite in the presence of r-phase in a Cu-Al-Ni-Mn-Fe Shape memory alloy," Materials Science and Engineering A., Vol. 481-482, pp. 494-499, 2008. 
3. R.Kainuma, X.J.Liu,I.Ohnuma, S.M.Hao, and K.Ishida, "Miscibility Gap of B2 Phase NiAl to Cu3Al Section of Cu-Al-Ni System," Intermetrallics, Vol. 13, pp. 655-661, 2005.

4. S. M. Chentouf, M. Bouabdallah, J-C. Gachon, E. Patoor, and A. Sari, "Microstucture and Thermodynamic Study of Hypoeutectoida Cu-Al-Ni Shape Memory Alloys," J. of Alloys and compounds, Vol. 470, pp. 507-514, 2009.

5. Z. Xiao, Z. Li, M. Fang, S. Xiong, X. Sheng, and M. Zhou, "Effect of Processing of Mechanical Alloying and Powder Metallurgy on Microstructure and Properties of Cu-Al-Ni-Mn Alloy," Materials Science and Engineering A. Vol. 488, No. 1-2, pp. 266-272, 2008.

6. V.Recarte, J.I.Perez-Landazabai, A.Ibarra, M.L.No, and J San Juan, "High temperature $\beta$ phase decomposition process in a Cu-Al-Ni shape memory alloy," Materials Science and Engineering A., Vol. 378, pp. 238-242, 2004.

7. J.I.Perez-Landazabai, V.Recarte, J.Campo, M.L.No, and J San Juan, "Neutron Diffraction Analysis of the $\beta$ Phase Decomposition Process in a Texture Free Cu-Al-Ni Shape Memory Alloy," Physica B, Vol.
350, pp. 1007-1009, 2004.

8. J.I.Perez-Landazabai, V.Recarte, M.L.No, and J San Juan, "Determination of the Order in r1 Intermetallic Phase in Cu-Al-Ni Shape Memory Alloy," Intermetallics, Vol. 11, pp. 927-930, 2003.

9. H-Y. Lee, J.-K. Roe, and A.Ikenaga, "Sliding Wear Properties for Ni-Al based Intermetallic Compound Layer Coated on Ductile Cast Iron by Combustion Synthesis," Wear, Vol. 260, pp. 83-89, 2006.

10. H-Y Lee, A. Ikenaga, S-H Kim, and K-B Kim, "The Effects of Induction Heating Rate on Properties of $\mathrm{Ni}-\mathrm{Al}$ based Intermetallic Compound Layer Coated on Ductile Cast Iron by Combustion Synthesis," Intermetallics, Vol. 15, pp. 1050-1056, 2007.

11. 이한영, 김태준, 조용재, "Ni-Al계 금속간화합물 코 팅에 미치는 고주파유도 가열 조건의 영향," 대한 금속재료학회지, 제 48권, 제2호, pp. 141-147, 2010.

12. M.M. Moshksar and M.Mirzaee, "Formation of NiAl Intermetallic by Gradual and Explosive Expthermic Reaction Mechanism During Ball Milling," Vol. 12, pp. 1361-1366, 2004.

13. ASM, ASM Handbook(Volume 3), pp. 2-24, 1992. 